\title{
The effect of temperature on the mechanical properties of hybrid FRP bars applicable for the reinforcing of concrete structures
}

\author{
Karolina Ogrodowska ${ }^{1, *}$, Karolina Łuszcz ${ }^{2}$, and Andrzej Garbacz ${ }^{1}$ \\ ${ }^{1}$ Warsaw University of Technology, Faculty of Civil Engineering, ul. Armii Ludowej 16, \\ 00-637 Warsaw, Poland
}

\begin{abstract}
One of the most common causes of the deterioration of concrete structures is the corrosion of steel reinforcement. Reinforcement made from fiber reinforced polymers (FRP) is considered to be an attractive substitution for traditional reinforcement. The most popular FRP reinforcing bars are made of glass fibers. Basalt fiber reinforced polymer (BFRP) is a relatively new material for reinforcing bars. The main drawback of BFRP bars is their low modulus of elasticity. A new type of bar made from hybrid fiber reinforced polymer (HFRP) in which a proportion of the basalt fibers are replaced with carbon fibers can be considered as a solution to this issue; such a bar is presented in this work. The HFRP bars might be treated as a relatively simple modification to previously produced BFRP bars. A different technical characteristic of the fibre reinforced polymer makes the designing of structures with FRP reinforcement differ from conventional reinforced concrete design. Therefore, it is necessary to identify the differences and limitations of their use in concrete structures, taking into account their material and geometric features. Despite the predominance of FRP composites in such aspects as corrosion resistance, high tensile strength, and significant weight reductions of structures - it is necessary to consider the behavior of FRP composites at elevated temperatures. In this paper, the effect of temperature on the mechanical properties of FRP bars was investigated. Three types of FRP bar were tested: BFRP, HFRP in which $25 \%$ of basalt fibers were replaced with carbon fibers and nHFRP in which epoxy resin was additionally modified with a nanosilica admixture. The mechanical properties were determined using ASTM standard testing for transverse shear strength. The tests were performed at $-20^{\circ} \mathrm{C},+20^{\circ} \mathrm{C},+80^{\circ} \mathrm{C}$ for three diameters of each types of bar.
\end{abstract}

\section{Introduction}

Nowadays, fiber reinforced polymers (FRP) are mostly used in civil engineering and the construction industry for the strengthening of existing reinforced concrete members (RC) such as beams, slabs, columns and prestressed components. They are also used in:

* Corresponding author: kar.ogrodowska@gmail.com 
structures fabricated entirely from advanced polymer composite material; FRP-concrete beam construction; the internal reinforcement of concrete members; the external reinforcement of metallic and RC structures [1-2]. FRP composite materials are able to provide structurally efficient alternatives to conventional construction materials with regard to such aspects as high resistance to chemically aggressive environments, high tensile strength, high fatigue strength, low density, the possibility of using elements of any length without making joints and ease of transporting material [3].

However, FRP materials, like all engineering materials, undergo mechanical and inservice adjustment in different ways due to environmental effects. One situation which does cause major durability concerns for FRP composites is the impact of elevated temperature and fire behavior [1].

Currently, the most widely described influence of high temperature on FRP composites in the literature concerns the use of FRP composites in the strengthening of existing structures. The most commonly used FRP bars were glass fiber composites GFRP [4]. Recently, FRP bars with basalt fibers (BFRP) have become increasingly popular $[3,5,6]$. BFRP bars have many significant improvements over steel reinforcements as well as other FRP composites.

The literature results show that the tensile strength of FRP fibres is unaffected by elevated temperatures of up to around $500^{\circ} \mathrm{C}$. The reduction of mechanical properties FRP composites is the main by degradation of the polymer matrix. Changes in the polymer matrix mainly occur around the glass transition temperature and relate to its transition from a glassy state to a rubbery state and this is typically in the range of $40-120^{\circ} \mathrm{C}$ for matrices used for infrastructure applications $[6,7]$. In the literature [8-10], the effect of temperatures was investigated in the range of $20-600^{\circ} \mathrm{C}$ on BFRP, GFRP and CFRP (carbon FRP) bars. In each of these tests the effect of increased temperature on the results of the uniaxial tensile test was evaluated. The tensile test is a commonly method used to evaluation the mechanical properties of bars. However an important consideration during the test with this method is to ensure that failure occurs in the test specimen, not at the anchorage [9]. That is why a very important element in these tests was the development of the appropriate anchoring of samples to guarantee destruction in the central area of the test sample. The bars were heated to a set temperature and then kept there for 20-30 minutes to provide the target temperature throughout the sample cross section. Specified temperature phases:

1) Phase I $\left(20-100^{\circ} \mathrm{C}\right)$ - composite with low sensitivity of temperature- the values strongly depend on the glass transition temperature of the polymer; in this range, almost all samples retained about $90 \%$ of their original tensile strength and modulus of elasticity,

2) Phase II $\left(200-400^{\circ} \mathrm{C}\right)$ - composite with high sensitive of temperature - the degradation process is accelerated, the epoxide softens and melts. Most of the tested samples around $300^{\circ} \mathrm{C}$ retains $50 \%$ of the original tensile strength, and Young's modulus retains up to $70-80 \%$ of its original value,

3) Phase III $\left(500-600^{\circ} \mathrm{C}\right)$ - composite very high sensitivity of temperature, a significant part of the resin matrix decomposes. At this stage the composite degrades very quickly. The Young's modulus retains up to $20-40 \%$ of its original value. While the amount of transferred force is about $10-20 \%$ of the original tensile strength and depends largely on the degree of carbon fiber oxidation.

In accordance with the literature data, the thermal qualities of the epoxy polymers can be improved by the addition of $\mathrm{SiO}_{2}$ nanoparticles to the polymer matrix. However, in the preparation of a matrix with a stable and perfect structure and maximum glass transition temperature ( $\mathrm{Tg}$ ), the optimal content of nanoparticles should be determined and there should be consideration for a longer curing time and the possibility to obtain a homogeneous dispersion of particles in the polymer matrix. Non-compliance with the above conditions may result in an uncontrolled increase in the viscosity of the reaction 
system and the agglomeration of particles $[11,12]$. Of great importance is the fulfilment of the conditions associated with the correct addition of the modifier into the matrix and with the polymer curing process $[12,13]$.

In this study, the three types of bars developed at Warsaw University of Technology [14] were tested: BFRP (basalt fiber reinforced polymer), HFRP (hybrid fiber reinforced polymer) and nHFRP - HFRP containing an epoxy matrix modified with $3 \% \mathrm{SiO}_{2}$ nanosilica. The relatively small modulus of longitudinal elasticity of the BFRP bars causes undue exceeding of deflections and scratches in bent concrete elements reinforced with them. The solution to the above problem is to increase the stiffness of the BFRP bars by replacing a proportion of the basalt fibers with carbon fibers. So there was investigated the impact of this hybridization on FRP's mechanical properties and impact of the nanosilica admixture to nHFRP's glass transition temperature. Due to the high labor intensity uniaxial tensile test, an alternative FRP transverse shear test was proposed. In this test method is does not require a special anchorage design and preparation of samples is much more efficient.

\section{Experimental program}

\subsection{Material characterization}

The subjects of the study were three types of FRP bars:

- BFRP: basalt fiber reinforced polymer in which the content of basalt fiber fraction was $100 \%$,

- HFRP: hybrid basalt-carbon FRP in which the content of the basalt fibre fraction was $75 \%$ and the carbon fiber fraction placed in the core bar was $25 \%$,

- nHFRP: hybrid basalt-carbon with epoxy matrix modified by $3 \%$ nanosilica $\left(\mathrm{SiO}_{2}\right)$ with the same fiber arrangement as the HFRP bars.

The volume fraction of the epoxy resin was $20 \%$ to ensure a proper bonding. The volume fraction of the fibers was the same $-80 \%$ in all types of FRP bars. An epoxy system developed for the production of structural composites by pultrusion method was used as a matrix in hybrid composite bars. Following the manufacturer's recommendation, the individual components were mixed with a mechanical agitator. Also was prepared epoxy resin with the addition of nanosilica.
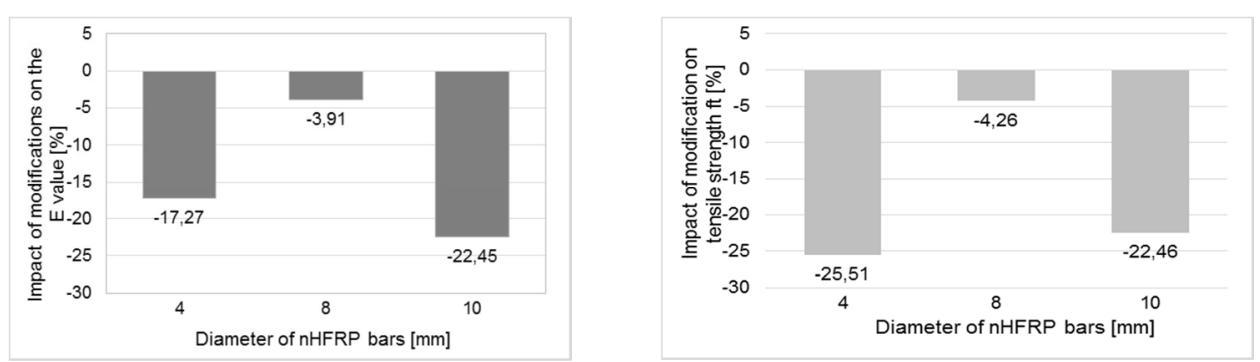

Fig. 1. Change the value of the average E module (left) and average tensile strength (right) of nHFRP bars in relation to the non-modified HFRP bars (room temperature).

Addition of $\mathrm{SiO}_{2}$ nanoparticles can improved the glass transition temperature of the epoxy polymers. Increasing Tg is a key element for increasing the fire resistance of FRP reinforced concrete structures [15]. In addition the most important benefits expected from resin after the nanosilica admixture are the following: increased fracture toughness, impact 
strength and modulus, improved scratch and abrasion resistance, reduced shrinkage upon curing and reduction of the coefficient of thermal expansion [16]. However, authors research showed the decrease of values of modulus of elasticity and tensile strength (Fig.1) after nanomodification.

\subsection{Test set up and procedure}

In real applications FRP composites in structures are service at low and high temperature due to the seasonal and daily temperature variations [7]. An exceptional situation is a fire and exposure of the structure to very high temperatures. However, research on full-scale fire test on FRP reinforced concrete slabs shows that the most influential factor in the fire resistance of FRP reinforced members was found to be FRP-concrete bond strength at elevated temperatures, the greatest decrease of which is recorded after exceeding the glass transition temperature of the composite. This is directly related with matrix becoming to rubbery state [16].

In the test has been chosen $+20^{\circ} \mathrm{C}$ as the typical service temperatures while $-20^{\circ} \mathrm{C}$ and $+80^{\circ} \mathrm{C}$ the temperature were selected as a temperature above glass temperature for tested resins. The investigated FRP bars were cut into $300 \mathrm{~mm}$ sections and subjected to the target temperature, and held there for 30 minutes. The bars were then allowed to stabilize at room temperature after heating or cooling. After reaching room temperature, they were subjected to shear strength testing.

The FRP transverse shear tests were conducted in accordance with the ACI 440.3R-04 guidelines [17] on a stand developed for the needs of the project. A testing machine was used with a loading capacity in excess of the shear capacity of the test specimen and calibrated according to ASTM. The specimen was mounted in the center of the shear apparatus, touching the upper loading device (Fig. 2). The load rise rate applied to each sample was $50 \mathrm{MPa} / \mathrm{min}$. The bars were tested to obtain the maximum shear force; the failure of the bar was accompanied by the sound of crack.
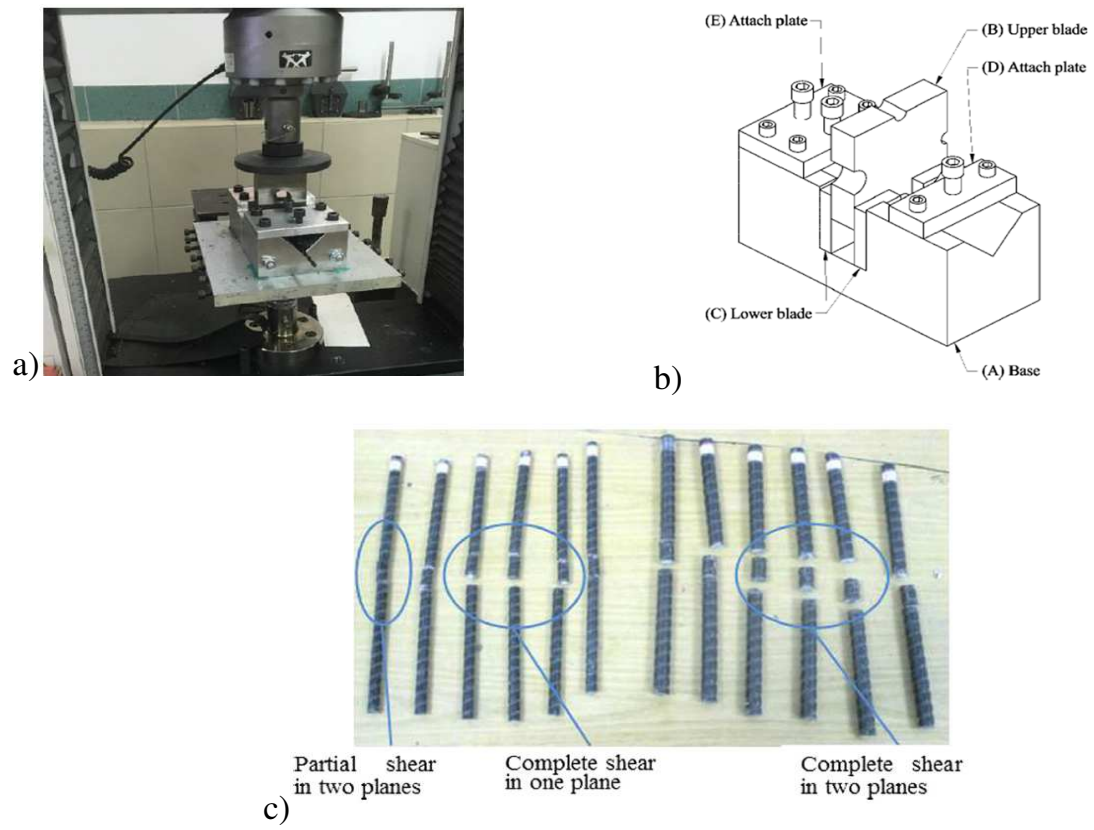

Fig. 2. a) the shearing machine in the integrated loading device, b) scheme of loading device according to ACI 440.3R-04 [17], C) typical fracture modes after shear test (according to [18]). 


\section{Results and discussions}

\subsection{Shear test results}

Based on the results of the transverse shear test mean shear stress was calculated according to the ACI standard [17] and presented in Fig. 3. In all tested bars, complete shear was observed in one shear plane. As part of assessing the precision of the results, the average standard deviation marked in Fig. 3 was calculated. The highest stability of the results was observed for the bars tested at room temperature $\left(+20^{\circ} \mathrm{C}\right)$ for all types of FRP bars.

The reduction of the shear strength (Fig. 3) of nanomodified bars compared to unmodified bars may be related to the agglomeration process. During the incorporation of $\mathrm{SiO}_{2}$ particles in a polymer matrix viscosity is increase. Nanosilica has the tendency of nanoparticles to agglomerate in polymeric matrices can hardly be controlled by conventional processing techniques due to the limited shear force during the mixing procedure. Agglomerates which act as weak points in the structure reduce properties of composites $[16,19,20]$. The agglomeration process may has been caused a reduction in the mechanical properties of the tested composites modified with nanosilica (Fig.1 and Fig. 3).

On the other hand, the average higher shear strength of some types of bars exposed to the temperature of $+80^{\circ} \mathrm{C}$ (Fig. 3) may result from insufficient hardening of the resin at the production stage. While the increase of the strength of bars which has been cooled to the temperature of $-20^{\circ} \mathrm{C}$, may indicate a stiffening of the polymer matrix and an apparent increase in the strength of the composite by increasing its brittleness. The process is similar to hardened steel. Both of these situations shows that the tested resin is sensitive to temperature fluctuations.

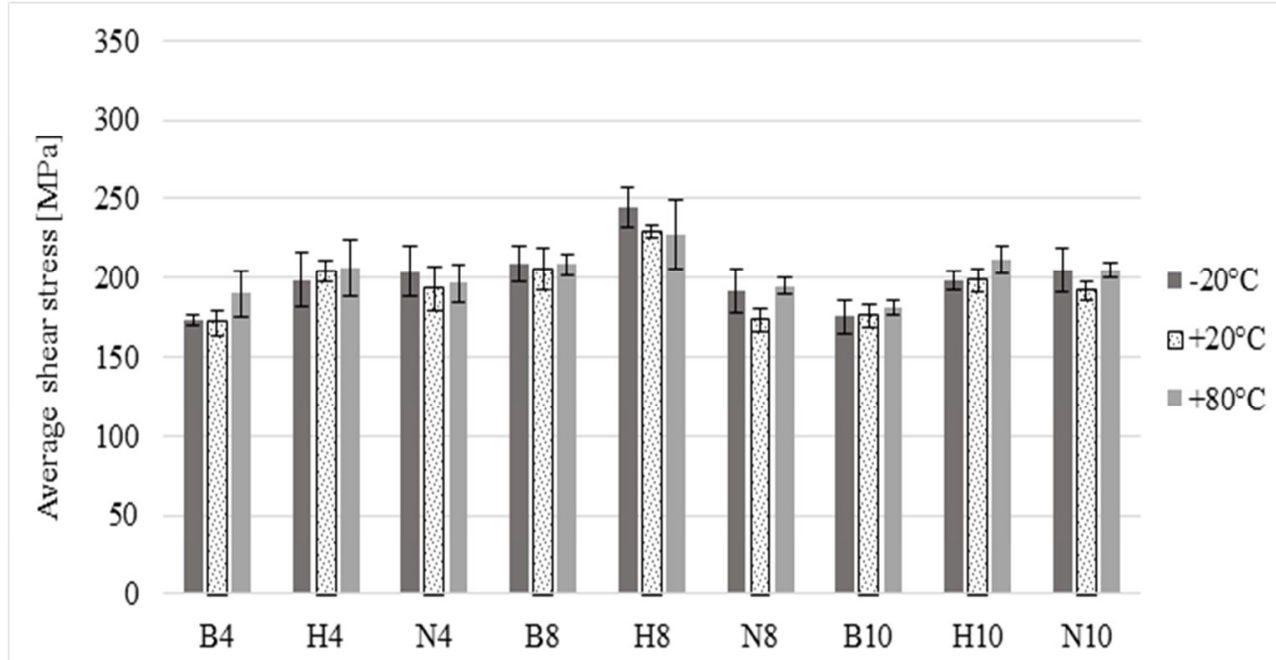

Fig. 3. Average shear stress depending on the type and diameter of the bar and its preheating or precooling temperature. B - basalt fibre reinforced polymer, $\mathrm{H}$ - hybrid fibre reinforced polymer, $\mathrm{N}$ - nano hybrid fibre reinforced polymer.

The summary diagram (Fig. 4) shows the dependence of the shear force on the shear displacement of the press actuator at a temperature of $+80^{\circ} \mathrm{C}$. The all bars were characterized by similar tendencies of shear stress, regardless of the diameters, types of resins and types of fibres. Each of the lines shows the three phases - the linear phase, the inflection phase, and the failure phase. 


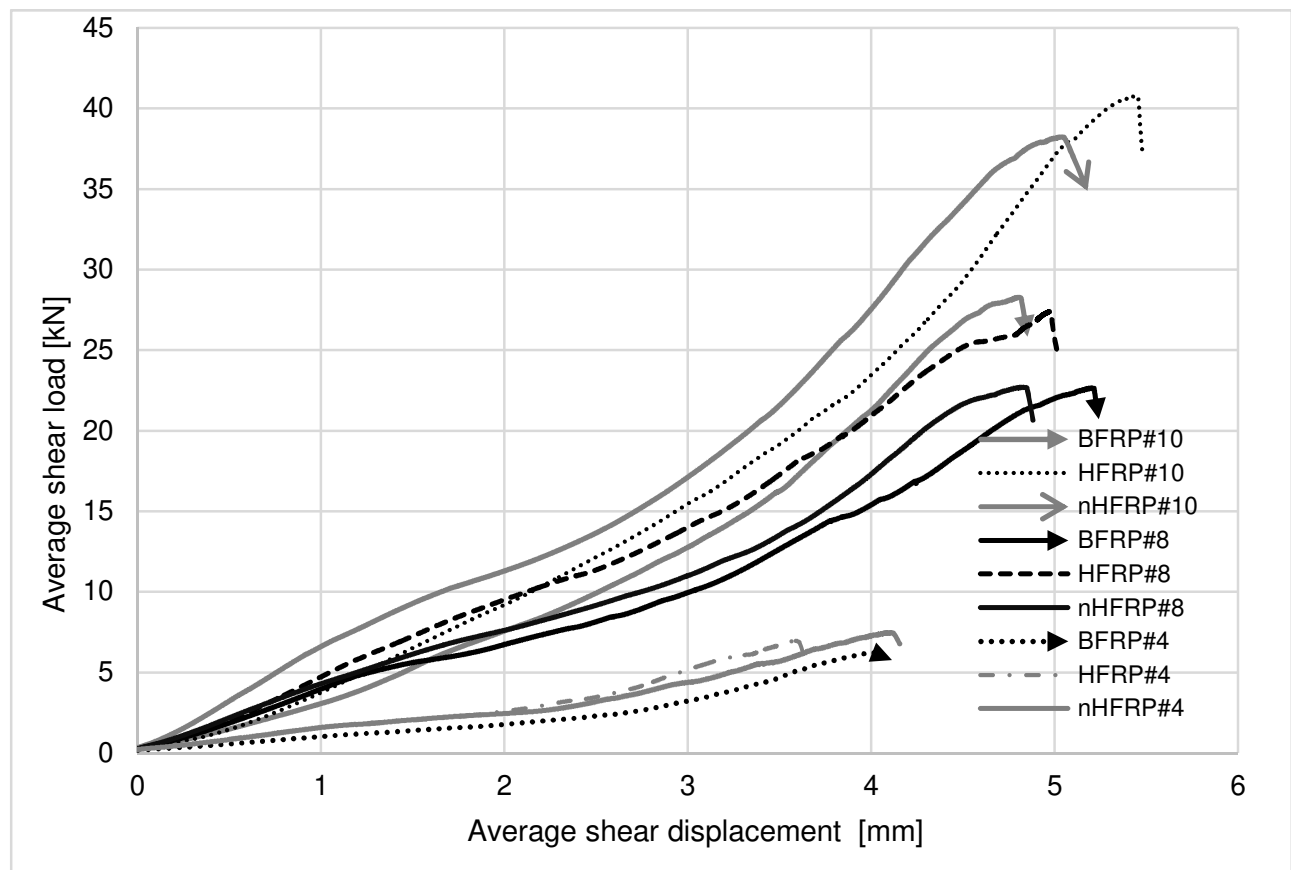

Fig. 4. Average shear load versus average shear displacement response at $+80^{\circ} \mathrm{C}$ for BFRP, HFRP and nHFRP for bars diameter of 4,8 and $10 \mathrm{~mm}$.

The not smooth fractured shear plane (Fig. 5) of the cross section which was created by pure shear, confirms the conclusions [18] that the shear resistance of the FRP bar is not defined only by the matrix deformation but also by the effect of fiber stretching, which bent near the position of the shear plane.

a)

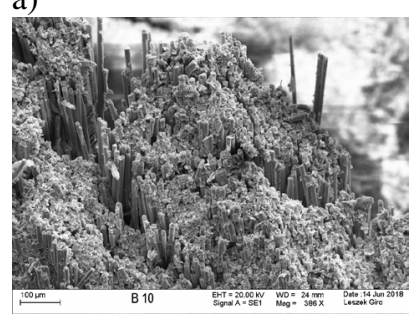

b)

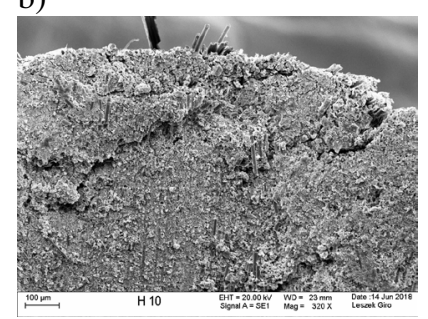

c)

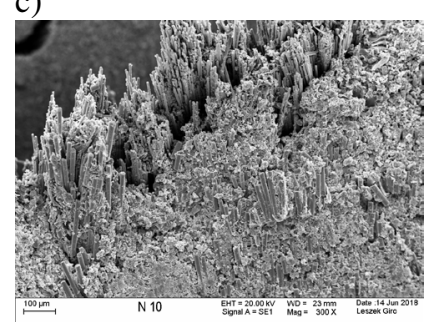

Fig. 5. Examples of cross section of: a) BFRP, b) HFRP and c) nHFRP bars after shear test at a temperature of $+20^{\circ} \mathrm{C}$

The FRP composites are heterogeneous material, their mechanical properties are influenced by the content of the fiber fraction, the accuracy of coating the fibers in the resin and type and any modifications of matrix. By continuing this type of research on FRP composites, it is possible specify factors significantly influencing. Determine the directions of material and technological changes that allow to reduce the variability of the properties of FRP bars. This can contribute to predict their behavior in the structure with greater accuracy and can cause broaden use of FRP in construction. 


\section{Conclusions}

On the basis of the test results, the following conclusions can be drawn:

- The temperature differences in the tests did not have a significant impact on the obtained results of shear strength values for both types of HFRP. This may have been caused by the bar holding time being too short during the test at the given temperature. Nevertheless, the influence of temperature changes on the condition of the epoxy resin is noticeable,

- In general, hybridization of FRP bar composition improved shear strength for each of the tested diameters,

- In order to analyses the results more fully, the morphology of the resin modified with nanosilica used as a matrix of nHFRP bars should be investigated in order to check whether a mixture of nanoparticle agglomeration appeared at the given amounts of nanosilica and the method of preparation of the mixture. The phenomenon to lower the stress in terms of tensile rating,

- The obtained results indicate that shear test can be used as a test for fast and relatively easy quality control. However, it is necessary to explain the relatively small difference in the shear strength for particular types of FRP bars in comparison to the results of tensile test.

Acknowledgement: The paper was prepared in the framework of the Internal Grant of the Faculty of Civil Engineering. In the paper, the experimental results of the NCBR project: "Innovative Hybrid FRP composites for infrastructure design with high durability”; NCBR: PBS3/A2/20/2015 were used.

\section{References}

1. C. Hall, J. Chen, L. Hollaway, ICE manual of construction materials POLYMERS AND POLYMER FIBRE COMPOSITES 60,109 (London 2010)

2. A.Siddika, Md. Abdullah Al Mamun, W. Ferdous, R. Alyousef, Eng. Fail. Anal. 111 (2020)

3. R. Kotynia, Wzmacnianie żelbetowych belek na ścinanie za pomoca kompozytów polimerowych, (Łódź 2011) (in Polish)

4. T.Siwowski, Mosty z kompozytów FRP, (2018) (in Polish)

5. A.Garbacz, A., M.Urbański, A.Łapko In Advanced Material Research 1129, 233-241 (2015)

6. K. Porotchenko, E. Szmigiera, M. Urbanski, A. Garbacz, P. Narloch, P. Lesniak, Mater. Sci. Eng, 661 (2019)

7. Y. Fang, Z. Fang, R. Jiang, Z. Jiang, D. Zhu Compos. Struct. 231 (2020)

8. B. Yu V. Kodur Compos. Part B-Eng. 58, 510-517 (2014)

9. Y. Wang, P. Wong i V. Kodur Compos. Struct. 80 (1), 131-140 (2007)

10. R. J. Hamad, M. M. Johari i R. H. Haddad Const. Build. Mater. 142, 521-535 (2017)

11. A.Allahverdi, M. Ehsani, H. Janpour, S. Ahmadi Prog. Org. Coat. 75 (4), 543- 548 (2012)

12. I. Barabanova, O.E. Philipova, A. A. Ashadskii, A. R. Khokhlov Procedia Chemistry 4, 352-359 (2012)

13. S. K. Singh, A. Kumar, A. Jain Materials Today: Proceedings 5 (2), 6339-6344 (2018)

14. A. Garbacz, E. D. Szmigiera, K. Protchenko, M. Urbański International Congress on Polymers in Concrete 1, 653-658 (Springer Washington USA 2018) 
15. H. Hajiloo, M.F. Green, M. Noël, N. Bénichou, M. Sultan, Compos. Struct. 179, 705719 (2017)

16. M. S. Sreekala, C. Eger, Polym. Composite 1, 91-105 (2005)

17. ACI 440.3R-04 (2004)

18. X. Wang, Z. Wang, Z. Wu and F. Cheng, Constr. Build. Mater. 30 781-789 (2014)

19. J. Macan, K. Paljar, B. Burmas, G. Spehar, M. Leskovac, A. Gajovic, J. Therm. Anal. Calorim. 127 (1), 399-408 (2017)

20. M. M. Alavi Nikje, M. Khanmohammadi, and A. Bagheri Garmarudi, Nanotechnology in Construction 3: Proceedings of the NICOM3 163-167 (2009) 